what will be its effect upon the typical examples in the text, worked first by the new process, and secondly by the old method of double altitude.

On page 30 an example $(\$ 32)$ is taken from Lecky, which will answer the purpose.

The data are as follows. Lat $\operatorname{DR} 32^{\circ} 15^{\prime} \mathrm{N}$.

March 7, 1880. Times by chton. Altitude. Bearing.

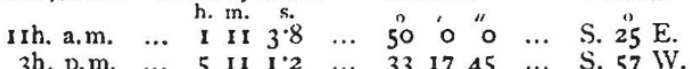

Sun's declination, $459^{\prime} 15^{\prime \prime} \mathrm{S}$. for first observation; $4^{\circ} 55^{\prime} 30^{\prime \prime} \mathrm{S}$. for second observation.

Let us suppose that an error of $2^{\prime}$ occurs in the second altitude, the one treated for reduction to the meridian.

The error in latitude ( $d l)$ produced by an error in altitude $(d z)$ is given approximately by the formula

$$
d l=\sec \mathbf{A}_{1} \cdot d z,
$$

where $A_{1}$ is the azimuth of the body.

Thus $d l=\sec 57^{\circ} \times 2^{\prime}$, or $3^{\prime} 40^{\prime \prime}$ nearly.

But if treated, so as to take in both observations, by the double altitude process,

$$
d l=\frac{\sin A_{2}}{\sin \left(A_{1}+A_{2}\right)} d z
$$

where $A_{1}=57^{\circ}, A_{2}=25^{\circ}$, the azimuths being reckoned from south in each case. Thus

$$
d l=\frac{\sin 25^{\circ}}{\sin 82^{\circ}} 2^{\prime} \text { or } 51^{\prime \prime} .
$$

So that in one case a reasonable error in altitude gives an error in latitude of nearly $4^{\prime}$, in the other of less than $I^{\prime}$.

One other instance will perhaps suffice. On page 36 an example from Riddle is worked out, wherein an error of $2^{\prime}$ in altitude would produce an error of $18^{\prime}$ upwards in latitude.

Such a result at once condemns the observation. Indeed, for the purpose of accurate determination of latitude, the double altitude stands out among the various methods a very king. In other cases, as in the meridian altitude, we are satisfied if the latitude is no more in error than the original observation. In a double altitude, taken under advantageous conditions, only a fraction of the error in altitude appears in the final result.

It is somewhat remarkable that Mr. Buller's evident appreciation of Sumner methods has not made him more familiar with the main principles which apply equally to all classes of observations.

Every observation furnishes the observer with a circle upon the globe, a straight line upon the Mercator's chart, on which to place his position. The circle has the sun's projection on the earth for its centre. 'The line has the sun's line of bearing perpendicular to it.

If this line of position is inclined at a very acute angle to the meridian, that is, if the body observed is near the prime vertical, it is evident that a very small increase in the perpendicular drawn from the sun to the line of position, that is, a very small increase of zenith distance, will produce relatively a very large difference of latitude. And this condition, coupled with the impossibility of obtaining accurate altitudes at sea, is sufficient to account for the restriction of ex-meridian observations to a point or two in azimuth from the meridian.

The British seaman, therefore, had better pause before he throws overboard his Norie or his Raper, and takes to his heart the new Buller methods.

The greatest self-confidence, the most implicit belief in the reality of the mission to which he has been called, will not enable Mr. Buller to find the latitude accurately by a single altitude near the prime vertical, for the very simple reason that the error (even when supposed small) which must be expected in the altitude produces a large error in the latitude, and thus vitiates the result.

If he would make the ex-meridian method available as he proposes to do, at almost any time of day, the author must supplement his treatise by the invention of some appliance for measuring altitudes very much superior to any now in use.

Pending its production the very pertinent question asked in page 36 , "We have known long enough how to get a fairly correct $A$. T. S. from an observation near the Prime Vertical and the latitude I). R., but who has yet shown how to obtain the True Latitude"? must re. main unanswered.

There is indeed freshness in the "New Method of Navigation," Part 1., but no light. 'That perhaps will be supplied by Part II.

G.

\section{VOICES FROM ABROAD}

THE following literal translation of parts of an article recently published in the Chemiker Zeitung (Nos. 85 and 86,1893 ) is an appropriate addendum to a recent article of mine in this journal. It must be sorrowfully admitted that in essential particulars the picture is a trae one.

HENRY E. ARMSTRONG.

"Notwithstanding the enormous industrial development of England, the appreciation of science by technical workers is inconceivably slight, the main cause being deficient comprehension. The Englishman is conservative in all his customs, in his way of living, and not less in his methods of manufacturing, so that there are still very many manufacturers who would be as little prepared to place the control of their works in the hands of a scientific chemist as to convert them into philanthropic institutions. At present great efforts are certainly being made to alter this condition of affairs by the aid of technical schools modelled on German lines, but opinions as to the value of these schools are as yet much divided; and, indeed, for various reasons their ultimate success is doubted. In the first place, it is to be borne in mind that these institutions are not under State control, but are governed and controlled by local boards. Moreover, the preliminary training which their students have received is not to be compared with that of students in the German institutions, as an education such as is given in the German Realschulen and Gymnasiums - of the character given in England at most by the grammar schools-is only procurable by those who are well off, owing to the enormously high school fees (about $£ 20$ or 400 marks a year). The possibility of consolidating and widening the technical training by a short subsequent course of scientific study at the University is absolutely out of the question in most cases, owing to its extreme costliness. It is therefore probable that these schools will but produce a number of half-educated persons wbo will take up positions as chemists and will thereby but bring the chemist proper into discredit.

"It is clear that under these circumstances there is but very little prospect that a chemist coming to England will find a suitable position. I cannot sufficiently strongly caution 'young chemists' against coming to England on the chance of picking up something good, even when provided with good introductions. So few analysts are in demand here that the chance of securing such a post is most uncertain. Works and laboratories in which scientific work is systematically carried on scarcely exist, not one even of the English aniline colour works having a scientific laboratory wortby of the name. The 'young chemist' has therefore very little chance of securing an appointment, as he does not possess the necessary qualification for a works post, that is to say experience,

NO. I 262 , voL. 49] 
and the volunteer nuisance is scarcely known here even by name. I can therefore only repeat that it is a very risky enterprise for a young, inexperienced chemist to come to England without a definite engagement, as so often happens. The result, with very few exceptions, is disillusionment, and many get into most unfortunate positions through financial pressure. The outlook is somewhat better for a chemist who has had experience and practice in works. But even such will find it infinitely more difficult to find posts in Fngland than it is either in Germany or Austria, and will do well to go to England only when offered a definite appointment. The thorough scientific training and business capacity of the German chemist is unreservedly recognised by all unprejudiced judges in contradistinction to that of his English colleague. In carrying on routine operations, the F.nglish chemist is doubtless as competent as the German chemist, even if he be not his superior, but in conducting and developing chemical industries on a scientific basis the latter is far in advance of the former.

"I need refer but briefly to the great chemical industries, as they are well enough known. Of these the first to be mentioned is the soda industry, including that of sulphuric acid and chlorine ; furthermore, tar-distilling, dyeing, calico-printing, the manufacture of iron, steel, copper, tin, and antimony, glass-making, the utilisation of fatty matters, the Scotch paraffin industry, and the manufacture of bichromate. These industries, excepting glass-making, employ a considerable number of chemists, although, in proportion to their output, not nearly so many as the German works. This is especially the case in dye works, calico-printing works, and in those dealing with fatty matters, many of which carry on their manufacture without chemists, or only with the aid of very imperfectly trained chemists, as every one here regards himself as a full-blown chemist who, after a most elementary preliminary training, has attended a technical course during one, or at most, two years. At least 80 per cent. of the chemists engaged in the industries mentioned are Englishmen, the remainder being either Germans or Swiss. I have never met a French chemist here. With few exceptions the condition of these industries during recent years must be characterised as dull and even as bad in some cases; they therefore offer the chemist little prospect of employment, and foreign capital is certainly not to be invested in them with advantage. Only dye-works and those utilising fatty matters offer a prospect to the experienced chemist, as these are both distinctly capable of being improved in position. The helpless condition of the English aniline colour works is peculiar, these having been simply stifled by the German works, which have developed with such giant strides. The English works eke out a miserable existence, and altogether do not employ as many chemists as are to be found in a similar German works of the fifth or sixth rank. Fuchsine, soluble blue, chrysoidine, Bismarck brown, and the few naphthol colours unprotected by patents, are almost the only colours manufactured. Not a single dyestuff of importance is made by any English firm alone, as scientific la. boratories such as are a matter of course in every German works exist here only in the most rudimentary form. Most of the chemists engaged in English aniline colour works are German (? ?), but the demand for chemists in these works is very small. The erection of such a works in England on the German model could only be achieved by the large (ierman firms engaged in this industry; it is another question whether it would pay. But the manufacture of pigments- of mineral colours and lakes-is certainly capable of development here. It is true there are a number of such works, but these rarely employ a chemist, and still more rarely one who has had a thorough scientific training. Consequently, enormous quantities of lakes are imported, especially for printing oil-cloths and carpets, which might equally well be manufactured on the spot. The necessary capital would be not an inconsiderable one, and may be estimated at, at least, 1 50,000 marks. Competent chemists in this branch can probably count on easily finding employment here.

"The manufacture of fine chemicals, which at present are almost entirely imported from Germany and France, is certainly capable of considerable development here. Of these may be mentioned especially, tannin, tartar emetic, pyrogallol, oxalic acid, cyanide of potassium, and most of the almost innumerable chemicals and preparations which are made use of in trade, and which are either not made here at all, or in altogether insufficient quantity and of poor quality. With reference to such articles, in the case of which wages form a considerable item in the cost of production, it is to be borne in mind that F.nglish wages are on the average considerably higher than German."

\section{THE EFFECTS OF LIGIIT ON THE ELICTRICAL DISCHARGE:}

W

HILE engaged on his classical experiments Hertz noticed that the appearance of the discharge be tween the two terminals of the oscillator was greatly changed upon the spark gap being illuminated by the light coming from another spark. This change was not due to an electrical action of the sparks, for it was equally well produced by other sources of light, such as the electric arc and burning magnesium, while all effect immediately ceased on interposing a plate of glass. Since the time when the above observations were made many experimentalists have investigated this subject and have obtained rather divergent results. In most cases the source of light employed has been the electric arc formed between carbon rods, though, with a view to increase the proportion of ultra-violet rays emitted, $13 i$, hat and Blondlot used carbon rods with aluminium cores, while Righi used a zinc rod for one terminal. Other observers have used the spark of an induction coil passing between terminals of copper, zinc, or aluminium. While Hertz had only noticed that the illumination of the discharging knobs increased the facility with which sparks passed, Wiedemann, Ebert and Hallwachs found that it was only when the negative terminal was illuminated that this effect took place. More recent observations by Branly have led to this view being modified, for he finds that on illuminating a piece of zinc by the sparks of a large induction coil produced between aluminium terminals, if the source of light is sufficiently near to the plate, the loss of charge is nearly as rapid for a positive as for a negative charge. On increasing the distance between the spark and the charged plate, the decrease in the rate of loss of charge is much more rapid for positive than for negative charges, and thus at some distance from the source of light the negative charge is the only one which is appreciably affected. Hence radiation of certain kinds increases the rate at which a positively charged body loses its charge, just as in the case of a negative charge, but the rays which are active in the case of positive electricity are absorbed by even a small thickness of air, while those rays which are unabsorbed are still able to accelerate the discharge of a negatively charged body.

After having made a series of experiments in air at ordinary pressures, Stoletow on the onc hand, and Righi on the other, have investigated the influence of pressure on the phenomenon, and have both found that the effect increases with a decrease of pressure, while Stoletow has shown that if the rarefaction is carried to the extreme limit there exists a pressure, after which the effect decreases as the pressure is further diminished.

An experiment of Bichat's seems to show that the loss No. 1262 , vol. 49] 